\section{Nonlinear Optical Chromophores with Configuration-Locked Polyenes Possessing Enhanced Thermal Stability and Chemical Stability}

\author{
Ching-Fong Shu,* Yuan-Cheng Shu, and \\ Zhi-Hao Gong
}

Department of Applied Chemistry, National Chiao Tung University, Hsin-Chu, Taiwan, 30035, R. O. C.

\section{Shie-Ming Peng and Gene-Hsiang Lee}

Department of Chemistry and Instrumentation Center, National Taiwan University, Teipei, Taiwan, 10764, R. O. C.

Alex K. Y. J en

Department of Chemistry, Northeastern University, 360 Huntington Avenue, Boston, Massachusetts 02115

Received J une 9, 1998

Revised Manuscript Received J uly 13, 1998

Nonlinear optical (NLO) polymers have been extensively studied because of their potential applications in electrooptic devices. ${ }^{1}$ The bulk NLO response of such polymeric materials originates principally from the noncentrosymmetric alignment of NLO chromophores incorporated in the poled polymers. Dipolar chromophores used in NLO applications are generally represented as $D-\pi-A$, where $D$ is an electron donor group, A an electron acceptor group, and $\pi$ an el ectronconjugated bridge linking D/A moieties. In such molecules, the donor and acceptor substituents provide the requisite ground-state charge asymmetry, whereas the $\pi$-conjugation system provides a pathway for the redistribution of electric charges under the influence of electric fields. Structure-property relationships that have been established indicate that the molecular optical response $(\beta)$ increases with increasing donor and acceptor strengths and with increasing $\pi$-conjugating length. ${ }^{2}$ Since their neutral and charge-separated states consist of similar $\pi$-systems of alternating single and double bonds, polyenes provide the most effective pathway for the efficient charge transfer between the donor and acceptor groups. ${ }^{3}$ For the design and synthesis of more efficient NLO chromophores, polyenes are good candidates as $\pi$-conjugated units to optimize $\beta$. However, extended polyene $\pi$-bridge systems suffer from the disadvantage of not being sufficiently thermally

(1) (a) Prasad, P. N.; Williams, D. J . Introduction to Nonlinear Optical Effects in Molecules and Polymers; J ohn Wiley \& Sons: New York, 1991. (b) Kanis, D. R.; Ratner, M. A.; Marks, T. J . Chem. Rev. 1994, 94, 195-242. (c) Dalton, L. R.; Harper, A. W.; Ghosn, R.; Steier, W. H.; Ziari, M.; Fetterman, H.; Shi, Y.; Mustacich, R. V.; J en, A. K-Y.; Shea, K. J . Chem. Mater. 1995, 7, 1060-1081.

(2) (a) Cheng, L. T. Tam W: Marder, S. R. Steigman, A. E. Rikken, G.; Spangler, C. W. J . Phys. Chem. 1991, 95, 10631-10643. (b) Cheng, L. T.; Tam. W.; Marder, S. R.; Steigman, A. E.; Rikken, G.; Spangler, C. W. J . Phys. Chem. 1991, 95, 10643-10652.

(3) (a) Marder, S. R.; Beratan, D. N.; Cheng, L.-T. Science 1991 252, 103-106. (b) Blanchard-Desce, M.; Alain, V.; Bedworth, P. V.; Marder, S. R.; Fort, A.; Runser, C.; Barzoukas, M.; Lebus, S.; Wortmann, R. Chem. Eur. J . 1997, 3, 1091-1104. stable, making them unsuitable for device applications, where chromophores with thermal stabilities exceeding $200{ }^{\circ} \mathrm{C}$ are often required in order to meet the requirements of material processing and device fabrication. ${ }^{1,4}$

Recently, we have devel oped a synthetic strategy for preparing NLO chromophores with an interposed conjugated triene segment which contains all but two of the methine groups incorporated into a six-membered ring system and have demonstrated that the configuration-locked polyene approach resulted in chromophores with enhanced thermal stabilities. ${ }^{5}$ In this report, we would like to extend the configuration-locked approach to NLO chromophores, where the $\pi$-conjugated methine chains are fully embeded into plane-rigidified, annulated rings. Precedent for the use of fused-ring systems to rigidify polyenes is found in heptamethine-cyanine dyes, which showed higher photostabilities than the analogous nonrigidified compounds. ${ }^{6}$ More recently, dipolar polyenes for organic photor efractive materials, in which the methine chain is plane-rigidified by a hydronaphthalene frame designed to prevent isomerization and to provide thermal and photochemical stability, have also been reported. ${ }^{7}$

Scheme 1 illustrates the synthetic route for the preparation of the planerigidified polyene chromophores. Reaction of commercially available dimedone (5,5-dimethyl-1,3-cyclohexanedione) with trimethyl orthoformate yielded methyl enol ether $\mathbf{1}$. Robinson annulation of $\mathbf{1}$ through regiosel ective deprotonation by using LDA followed by alkaline treatment gave dienone methyl ether $\mathbf{2 .}{ }^{8}$ Repeated Robinson annulation of $\mathbf{2}$ produced trienone methyl ether $\mathbf{3}$. Though the corresponding anal ogues of compounds $\mathbf{2}$ and $\mathbf{3}$ without the dimethyl substituents have been synthesized through Birch reduction, ${ }^{6,9}$ our synthetic method provides a facile and flexible route to the polyenones. Reactions of $\mathrm{p}-\mathrm{N}, \mathrm{N}^{\prime}-$ diethylaminophenyllithium with compounds $\mathbf{2}$ and $\mathbf{3}$, respectively, led to ketones with a double-annulated ring (4) and a triple-annulated ring (5). A Knoevenagel condensation of ketones $\mathbf{4}$ and $\mathbf{5}$ with malononitrile afforded dicyanovinyl-substituted chromophores $\mathbf{6}$ and 7. To compare their thermal stabilities, the analogous nonrigidified chromophores $\mathbf{6 a}$ and $7 \mathbf{a}$ were also pre pared using literature procedures.5b,10 These com-

(4) (a) Moylan, C. R . Twieg, R L : Lee V. Y : Swanson, S. A Betterton, K. M.; Miller, R. D. J . Am. Chem. Soc. 1993, 115, 12599 12600. (b) Gilmour, S.; Marder, S. R.; Perry, J . W.; Cheng, L.-T. Adv. Mater. 1994, 6, 494-496. (c) Gilmour, S.; Montgomery, R. A.; Marder S. R.; Cheng, L.-T.; J en, A. K.-Y.; Cai, Y.; Perry, J . W.; Dalton, L. R. Chem. Mater. 1994, 6, 1603-1604. (d) Rao, V. P.; Wong, K. Y.; J en, A. K.-Y.; Drost, K. J . Chem. Mater. 1994, 6, 2210-2212.

(5) (a) Shu, C.-F.; Tsai, W.-J .; J en, A. K.-Y. Tetrahedron Lett. 1996 37, 7055-7058. (b) Shu, C.-F.; Tsai, W.-J .; Chen, J .-Y.; J en, Alex K.Y.; Zhang, Y.; Chen, T.-A. J . Chem. Soc., Chem. Commun. 1996, 22792280.

(6) Heilig, G.; Lüttke, W. Chem. Ber. 1987, 120, 1863-1866.

(7) Kippelen, B.; Marder, S. R.; Hendrickx, E.; Maldonado, J . L.; Guillemet, G.; Volodin, B. L.; Steele, P. D.; Enami, Y.; Sandalphon; Yao, Y.J .; Wang, J . F.; Röckel, H.; Erskine, L.; Peyghambarian, N. Science 1998, 279, 54-57.

(8) Takahashi, K.; Suzuki, T.; Hirama, M. Tetrahedron Lett. 1992 33, 4603-4604.

(9) (a) Marshall, J :; Andersen, N. H. J . Org. Chem. 1965, 30, 12921294. (b) Kotlarek, W. J . Org. Chem. 1975, 40, 2841-2842. 2730 
Scheme 1. Synthesis of Plane-Rigidified Polyene Chromophores ${ }^{a}$

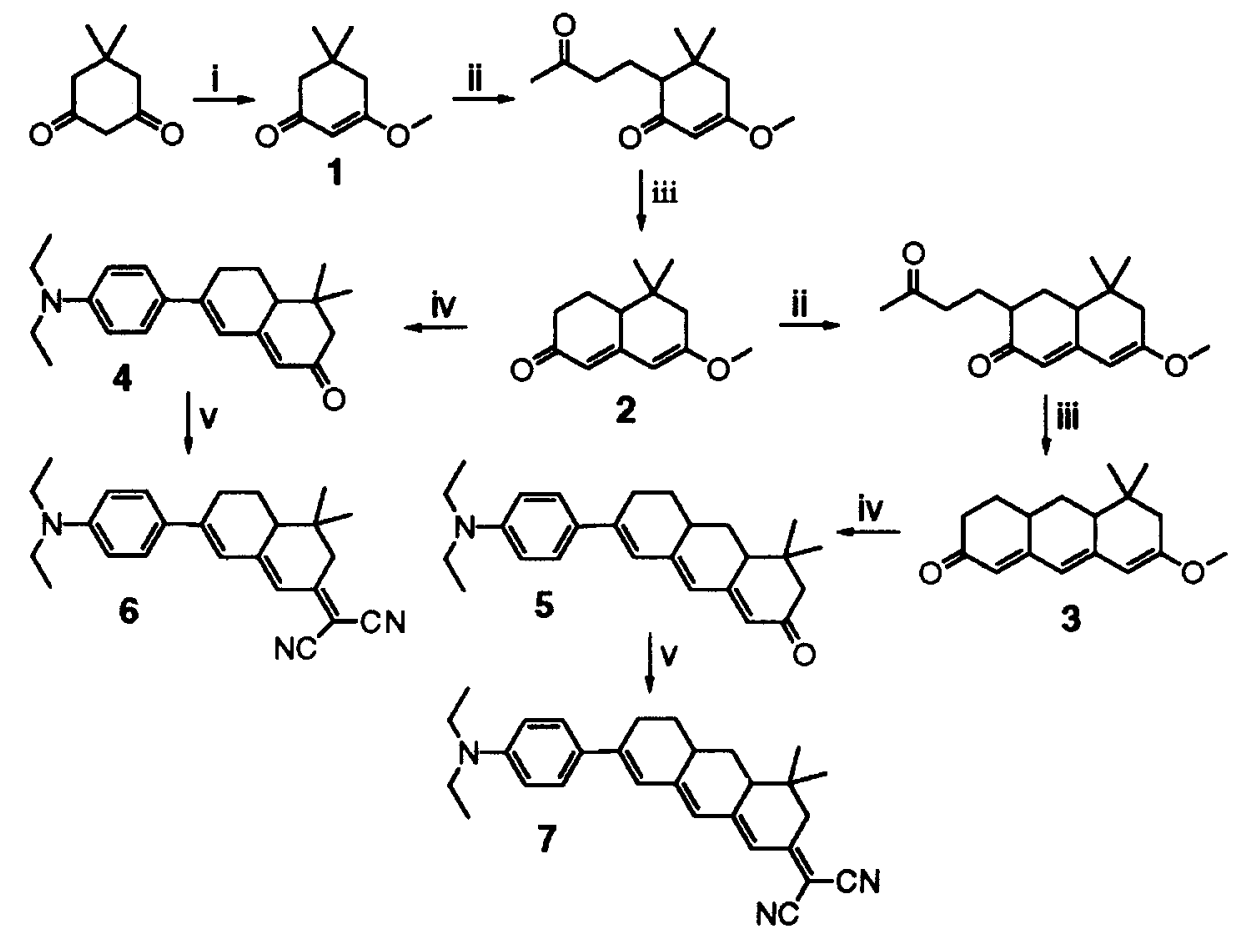

a Reagents: (i) $\mathrm{HC}(\mathrm{OMe})_{3}, \mathrm{H}^{+}$; (ii) LDA, MVK/THF, $-78^{\circ} \mathrm{C}$; (iii) $\mathrm{NaOMe/MeOH}, 60^{\circ} \mathrm{C}$; (iv) p-N,N-diethylaminophenyllithium/THF ; (v) $\mathrm{Ch}_{2}(\mathrm{CN})_{2}$.

pounds were characterized by electronic absorption, ${ }^{1} \mathrm{H}$ NMR, and ${ }^{13} \mathrm{C} N M R$, as well as high-resolution mass spectroscopy (HRMS). ${ }^{11}$

The absorption spectra of the push-pull polyenes investigated in the present work display intense chargetransfer (CT) bands in the visible region. The wavelengths of the absorption maxima $\left(\lambda_{\max }\right)$ are shown in Table 1. The configuration-locked polyene chromorphores have a slight blue-shifted CT band when compared to the corresponding nonrigidified ones. This result suggests that incorporation of the methine groups into rigidified, annulated rings would not significantly reduce the planarities and the electron del ocalization efficiencies of the $\pi$-conjugation systems. The molecular structures of chromophores $\mathbf{7}$ and $\mathbf{7 a}$ in the solid state were determined by X-ray crystallography. The polyenic chains of both molecules exhibit a nearly planar zigzag conformation. The phenyl ring of the donor moiety is slightly twisted (twist angle $=4^{\circ}$ for $\mathbf{7}$ and $11^{\circ}$ for $\left.7 a\right)$ with respect to the plane of the polyenic chains. The dicyanovinyl acceptor lies almost in the

(11) ${ }^{1} \mathrm{H}$ and ${ }^{13} \mathrm{C}$ NMR spectra were recorded using $\mathrm{CDCl}_{3}$ as solvent. All chemical shifts are reported from TMS in ppm, and coupling constants are in hertz. ${ }^{1} \mathrm{H}$ NMR 6: $\delta 0.80(\mathrm{~s}, 3 \mathrm{H}), 1.17(\mathrm{~s}, 3 \mathrm{H}), 1.18(\mathrm{t}$, $6 \mathrm{H}, \mathrm{J}=6.9), 1.40-3.00(\mathrm{~m}, 7 \mathrm{H}), 3.39(\mathrm{q}, 4 \mathrm{H}, \mathrm{J}=6.9), 5.58(\mathrm{~s}, 1 \mathrm{H})$, $6.64(\mathrm{~d}, 2 \mathrm{H}, \mathrm{J}=9.3), 6.69(\mathrm{~s}, 1 \mathrm{H}), 7.46(\mathrm{~d}, 2 \mathrm{H}, \mathrm{J}=9.3) .7: \delta 0.79(\mathrm{~s}$, $3 \mathrm{H}), 1.16(\mathrm{~s}, 3 \mathrm{H}), 1.17(\mathrm{t}, 6 \mathrm{H}, \mathrm{J}=6.9), 1.18 \sim 2.80(\mathrm{~m}, 10 \mathrm{H}), 3.38(\mathrm{q}$ $4 \mathrm{H}, \mathrm{J}=6.9), 6.15(\mathrm{~s}, 1 \mathrm{H}), 6.53(\mathrm{~s}, 1 \mathrm{H}), 6.61(\mathrm{~s}, 1 \mathrm{H}), 6.64(\mathrm{~d}, 2 \mathrm{H}, \mathrm{J}=$ 9.0), $7.43(\mathrm{~d}, 2 \mathrm{H}, \mathrm{J}=9.0)$. 7a: $\delta 1.18(\mathrm{t}, 6 \mathrm{H}, \mathrm{J}=7.0), 3.39(\mathrm{q}, 4 \mathrm{H}, \mathrm{J}=$ 7.0), $6.40(\mathrm{dd}, 1 \mathrm{H}, \mathrm{J}=13.8,11.7), 6.58-6.76(\mathrm{~m}, 5 \mathrm{H}), 6.85(\mathrm{dd}, 1 \mathrm{H}, J$ $=13.8,10.4), 6.96(\mathrm{dd}, 1 \mathrm{H}, \mathrm{J}=14.1,11.4), 7.33(\mathrm{~d}, 2 \mathrm{H}, \mathrm{J}=9.0), 7.38$ (d, $1 \mathrm{H}, 12.0) .{ }^{13} \mathrm{C}$ NMR 6: $\delta 12.6,19.7,22.5,28.0,28.4,34.6,44.4$ $45.2,45.8,73.3,111.2,113.9,114.7,118.5,121.1,124.8,127.4,148.9$, 151.9, 157.2, 168.8. 7: $\delta 12.6,19.7,27.5,28.5,29.7,30.0,34.7,36.2$ $44.4,45.1,46.3,46.3,73.2,111.3,113.9,114.8,118.3,120.7,124.3$, $125.8,126.9,147.1,148.2,154.2,157.3,168.4 .7 a: \delta 12.6,44.5,77.9$, $111.5,112.7,114.7,122.9,123.3,123.8,127.8,129.5,141.8,147.4,148.8$ 151.2, 159.2. HRMS (m/z) 6: obsd 371.2367, calcd 371.2361 for $\mathrm{C}_{25} \mathrm{H}_{29} \mathrm{~N}_{3}$. 7: obsd 423.2683, calcd 423.2674 for $\mathrm{C}_{29} \mathrm{H}_{33} \mathrm{~N}_{3}$. 7a: obsd 303.1730, calcd 303.1735 for $\mathrm{C}_{20} \mathrm{H}_{21} \mathrm{~N}_{3}$.
Table 1. Electronic Absorptions and Thermal Stabilities

(n)
ing

same plane (twist angle $=3^{\circ}$ for 7 and $11^{\circ}$ for $7 a$ ). Bond length alternation (BLA), defined as the difference between the average length of carbon-carbon double and single bonds in the polyenic chain linking the donor and acceptor moiety, is a useful structural parameters to examine in developing structure-property relations for NLO chromophores. ${ }^{12}$ It has been shown that there is a direct correlation between BLA and molecular optical nonlinearity. The BLA values of $\mathbf{7}$ and $\mathbf{7 a}$ determined in the solid state are -0.066 and $-0.062 \AA$, respectively. This result further reinforces the suggestion that the rigidity of the framework of annulated 


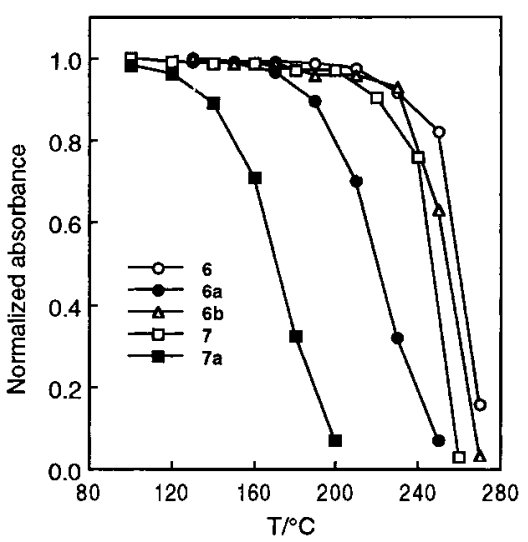

Figure 1. Thermal stability of $\mathbf{6}, \mathbf{6 a}, \mathbf{6 b}, \mathbf{7}$, and $\mathbf{7 b}$ heated isothermally at various temperatures for a 20 min interval, measured by following the change in absorbance of a 2 wt \% dye-doped polyquinoline thin film vs temperature.

rings does not diminish the planarities and the electron delocalization efficiencies of the polyenic chains and implies that for chromophores $\mathbf{7}$ and $\mathbf{7 a}$ the degrees of mixing between neutral and charge-separated canonical resonance forms as well as the second-order NLO effects should be similar.

In an effort to determine the thermal stability of these chromophores, we initially used differential scanning calorimetry (DSC, $10^{\circ} \mathrm{C} / \mathrm{min}$ ) measurements. ${ }^{4 a}$ The intercept of the leading edge of the thermal decomposition exotherm with the baseline of each DSC scan was assigned as the decomposition temperature $\left(T_{d}\right)$. Comparison of the $T_{d} S$ of rigidified NLO chromophores, 6 and $\mathbf{7}$, with those of corresponding nonrigidified ones, $6 \mathbf{a}$ and $7 \mathbf{a}$, reveals that the configuration-locking method provides a dramatic enhancement of molecular thermal stability. The semi rigid chromophore $\mathbf{6 b}^{5 \mathrm{a}}$ also shows enhanced thermal stability compared with $\mathbf{6} \mathbf{a}$, but the improvement is slightly lessened. It is noted that, as the order of the conjugation length of polyenes increases, the thermal stability of the nonrigidified chromophores apparently reduces; nevertheless, the enhancement of thermal stability due to the configuration-lock increases. For the reasons that the $T_{d}$ of $7 a$ is close to $T_{m}$ and that the $T_{d} S$ obtained from DSC may not reflect the thermal behavior for chromophores in the polymer system where the NLO chromophores will be used for device applications, we decided to examine the chromophores within polyquinoline (PQ-100, Maxdem) films. ${ }^{\text {bb }}$ Polyquinoline

(12) (a) Marder, S. R.; Perry, J . W.; Tiemann, B. G.; Gorman, C. B.; Gilmour, S.; Biddle, S.; Baurhill, G. J . Am. Chem. Soc. 1993, 115, 2524-2526. (b) Marder, S. R.; Gorman, C. B.; Tiemann, B. G.; Cheng, L.-T.J . Am. Chem. Soc. 1993, 115, 3006-3007. (c) Bourhill, G.; Brédas, J .-L.; Cheng, L.-T.; Marder, S. R.; Meyers, F.; Perry, J . W.; Tiemann, B. G. J . Am. Chem. Soc. 1994, 116, 2619-2620. (d) Marder, S. R.; Cheng, L.-T.; Tiemann, B. G.; Friedli, A. C.; Blanchare-Desce, M.; Perry, J . W.; Skindnøj, J . Science 1994, 263, 511-514. (e) Meyers, F.; Marder, S. R.; Pierce, B. M.; Brédas, J . L. J . Am. Chem. Soc. 1994, 116, 10703-10714. thin films containing 2 wt \% of chromophores on glass substrates were heated isothermally at various temperatures for $20 \mathrm{~min}$ intervals. The change in absorbance at the absorption maximum of the CT absorption band at various temperatures was determined, and the results are shown in Figure 1 . The thermal stabilities of chromophores evaluated within polymer system are consistent with the data from DSC measurements. For polymer films containing configuration-locked chromophores $\mathbf{6}, \mathbf{6 b}$, and $\mathbf{7}$, respectively, the absorbances started diminishing at $240{ }^{\circ} \mathrm{C}$, somewhat lower than expected from DSC measurements. It may be due to the sublimation of chromophore out of the polymer matrix through the uncovered side at the temperature near the glass transition temperature of polyquinoline $\left(250-260^{\circ} \mathrm{C}\right) .{ }^{13}$

In summary, we have developed a feasi ble synthetic methodology for obtaining dipolar NLO chromophores with all the methine groups incorporated into rigidified annulated rings. The configuration-locking approach furnishes NLO chromophores possessing enhanced thermal stability for device applications. The data from UV-vis spectroscopy and X-ray crystallography reveal that the rigidity of the annulated rings does not diminish the planarity and the electron delocalization efficiency of the polyenic chain. In addition, the incorporation of the methine groups into rigidified annulated rings may also enhance the chemical stability of the chromophores by reducing the susceptibility of the polyenic chain to nucleophilic attack, such as Michael addition reaction, which may be occurs during the polymerization reaction in which nucleophiles such as amines may exist. Experiments to extend the $\pi$-conjugated system of chromophores by adding a thiophene ring to the polyenic chain via a condensation reaction of the ketone group of intermediates $\mathbf{4}$ and $\mathbf{5}$ with thiophenemethyl phosphonate are in progress. ${ }^{5 a}$ Electrooptic studies of these chromophores as guest materials in high $\mathrm{T}_{\mathrm{g}}$ polymer systems are also currently under investigation.

Acknowledgment. We thank the National Science Council (R. O. C.) (NSC 87-2113-M 009-003) for financial support.

Supporting Information Available: Synthesis procedures for compounds $\mathbf{1}$ to $\mathbf{7}$ and X-ray crystallographic data for compounds $\mathbf{7}$ and $\mathbf{7 a}$ (12 pages). Ordering information is fiven on any current masthead page.

\section{CM980413N}

(13) (a) Pauley, M. A.; Guan, H. W.; Wang, C. H. J . Chem. Phys 1996, 104, 6834-6842. (b) A polyquinoline film doped with 2 wt $\%$ of p-diphenylaminodicyanovinylbenzene, which had $\mathrm{T}_{d}>380^{\circ} \mathrm{C}$ determined by DSC (ref 4a), also shows a significant decrease in the absorbance at $250{ }^{\circ} \mathrm{C}$. 